\title{
Adults have more male-biased sex ratios than first-winter juveniles in wintering duck populations
}

\author{
Kevin A. Wood* ${ }^{*}$, Kane Brides, Maurice E. Durham and Richard D. Hearn
}

\begin{abstract}
Background: The long-term monitoring of demographic changes in waterbird populations remains limited, but such information can be valuable for conservationists and waterbird managers. Biased sex ratios can indicate differences in survival rates between sexes. In particular, differences in the sex ratios of fledged juveniles and adults can provide insight into the development of male bias among populations.
\end{abstract}

Methods: In this study, we used data from individual birds captured over a 57-year period to assess the extent, and temporal variability in male bias in nine populations of ducks wintering in the United Kingdom: Gadwall (Mareca strepera), Northern Mallard (Anas platyrhynchos), Northern Pintail (Anas acuta), Common Pochard (Aythya ferina), Common Shelduck (Tadorna tadorna), Northern Shoveler (Spatula clypeata), Eurasian Teal (Anas crecca), Tufted Duck (Aythya fuligula), and Eurasian Wigeon (Mareca penelope).

Results: Overall, eight of these populations were significantly male-biased and adults were more male-biased than first-winter juveniles for all nine populations. The increased male bias among adults is consistent with the hypothesis that factors such as higher mortality of reproductive-age females during the breeding season is a major cause of male bias in duck populations. However, such predation cannot explain the male bias detected in first-winter juveniles in four of the populations. The temporal trends in male bias differed between adults and first-winter juveniles in Northern Mallard, Northern Pintail, Common Pochard, Common Shelduck, Eurasian Teal, Tufted Duck, and Eurasian Wigeon. Over the study period we found increased male bias among adult Northern Mallard, Northern Pintail, Common Pochard, Common Shelduck, and Tufted Duck as well as both adult and first-winter juvenile Northern Shoveler.

Conclusions: We provide evidence that among wintering duck populations, sex ratios are typically male-biased, with adults exhibiting stronger male-biased sex ratios than first-winter juveniles. Improved monitoring of sex ratios of wintering waterbirds would help to increase our understanding of changes in waterbird demography, population structure, and observed population trends; our study shows that birds caught during ringing projects can be a valuable source of such data.

Keywords: Anseriformes, Bird ringing, Demography, Population structure, Sex ratio, Waterfowl

*Correspondence: kevin.wood@wwt.org.uk

Wildfowl \& Wetlands Trust, Slimbridge, Gloucestershire GL2 7BT, UK

\begin{abstract}
Background
The relative numbers of individuals of different sexes within a population can provide valuable information to biologists (Leopold 1933; Mayr 1939; Sheldon 1998; Donald 2007). Unbalanced numbers of males and females among adults and fledged juveniles can result from uneven numbers at the embryo or hatchling
\end{abstract} original author(s) and the source, provide a link to the Creative Commons licence, and indicate if changes were made. The images or other third party material in this article are included in the article's Creative Commons licence, unless indicated otherwise in a credit line to the material. If material is not included in the article's Creative Commons licence and your intended use is not permitted by statutory regulation or exceeds the permitted use, you will need to obtain permission directly from the copyright holder. To view a copy of this licence, visit http://creativecommons.org/licenses/by/4.0/. The Creative Commons Public Domain Dedication waiver (http://creativeco mmons.org/publicdomain/zero/1.0/) applies to the data made available in this article, unless otherwise stated in a credit line to the data. 
stages (Bolen 1970). Yet, biased sex ratios among adults and fledged juveniles in populations with balanced embryo or hatchling sex ratios can indicate differential post-fledging survival rates of males and females (Sun et al. 2011; Bellebaum and Mädlow 2015; Ramula et al. 2018). In such cases, temporal changes in the sex ratios of adults and fledged juveniles can be used to infer corresponding changes over time in sex-specific survival rates, providing biologists with a useful tool for monitoring demographic changes in bird populations (Donald 2007).

Surveys of populations of adult and fledged juvenile small-bodied waterfowl (Anseriformes), including many duck species, have found male-biased sex ratios (e.g. Bellrose et al. 1961; Dean and Skead 1977; Owen and Dix 1986; Mitchell et al. 2008; Brides et al. 2017; Frew et al. 2018; Pöysä et al. 2019). In contrast, these species typically show balanced sex ratios among embryos and hatchlings (e.g. Blums and Mednis 1996). One explanation for male-biased sex ratios among adult duck populations is higher mortality rates of reproductive-age females during the breeding season, due to factors such as predation and physiological stress (Johnson and Sergeant 1977; Korschgen 1977; Ramula et al. 2018). A review by Donald (2007) found that biases in sex ratios were more severe in populations of threatened species than in non-threatened species. Highly male-biased sex ratios can therefore be a cause for concern to conservationists and wildlife managers. Fox and Cristensen (2018) argued recently that more information on the sex ratios of duck populations is needed to help conservationists and wildlife managers diagnose the demographic and environmental causes of fluctuating population sizes.

While studies of long-term trends in duck sex ratios remain scarce, some recent assessments have found that the sex ratios among adults and fledged juveniles can vary over time. For example, Brides et al. (2017) found that the sex ratio of Common Pochard (Aythya ferina) wintering in Europe and North Africa became increasingly male-biased between 1989/90 and 2016. A study by Lehikoinen et al. (2008a) similarly showed a clear increase in male bias among Common Eider (Somateria mollissima) in the Gulf of Finland and Denmark. Christensen and Fox (2014) reported that among ducks shot by hunters in Denmark, sex ratios showed inter-annual variability between 1982 and 2010, with some species showing trends towards greater male bias (e.g. Eurasian Wigeon Mareca penelope) or reduced male bias (e.g. Tufted Duck Aythya fuligula), with some species (e.g. Common Pochard) showing no consistent trend over time. Despite such studies, there remains a lack of routine monitoring of sex ratios among European duck populations (Fox and Cristensen 2018), and so whether such temporal trends also exist in the sex ratios of other European ducks is unknown for many species.

It is also currently unclear at which age class duck populations become male-biased. From the limited data that are available, the sex ratio among duck hatchlings is typically balanced (e.g. Blums and Mednis 1996), but at some point may become strongly male-biased (Bellrose et al. 1961; Owen and Dix 1986; Brides et al. 2017). Differences in the sex ratios of fledged juveniles and adults can provide insight into the development of male-bias among populations (Mitchell et al. 2008; Lehikoinen et al. 2008b). Similar male-bias in both adults and first-winter juveniles would indicate that higher mortality of adult females during breeding could not be the main reason for a male-biased sex ratio (Lehikoinen et al. 2008b). Instead, differences in the survival rates of male and female juveniles could produce biased sex ratios among first-winter juveniles which would later persist among adults (e.g. Eberhart-Phillips et al. 2018).

In this study, we used data on the relative abundances of males and females of nine duck species captured for bird ringing programmes to assess whether adults and first-winter juveniles showed the same species-specific trends in male bias. We tested three predictions regarding male bias in our focal duck populations. Our first prediction was that all of our species would be male-biased, as has been found for many duck populations (Bellrose et al. 1961; Owen and Dix 1986; Brides et al. 2017). Our second prediction was that for each species the sex ratio of adults would be more male-biased than the sex ratio of first-winter juveniles, in accordance with the high predation rates of reproductive-age females during the breeding season (Johnson and Sargeant, 1977; Ramula et al. 2018). Finally, our third prediction was that the male bias among adults, but not first-winter juveniles, would have increased over time, especially in declining species such as Common Pochard, in accordance with the hypothesis that higher mortality rates of reproductive-age females has been largely responsible for observed shifts towards more male-biased sex ratios (Brides et al. 2017).

\section{Methods}

\section{Capture and assessment of individuals}

Data were available for individuals that were captured as part of long-term duck ringing programmes (Mitchell and Ogilvie 1996) at 30 sites across the United Kingdom between winters 1963/64 and 2019/20 (Fig. 1). As our aim was to assess winter sex ratios, we restricted our analyses to only those individuals caught between October and February (inclusive). Principal capture methods were decoy traps, consisting of a blind-ended, cone-shaped tunnel into which individual ducks were lured with the use of food (e.g. wheat grains) or model decoys and 


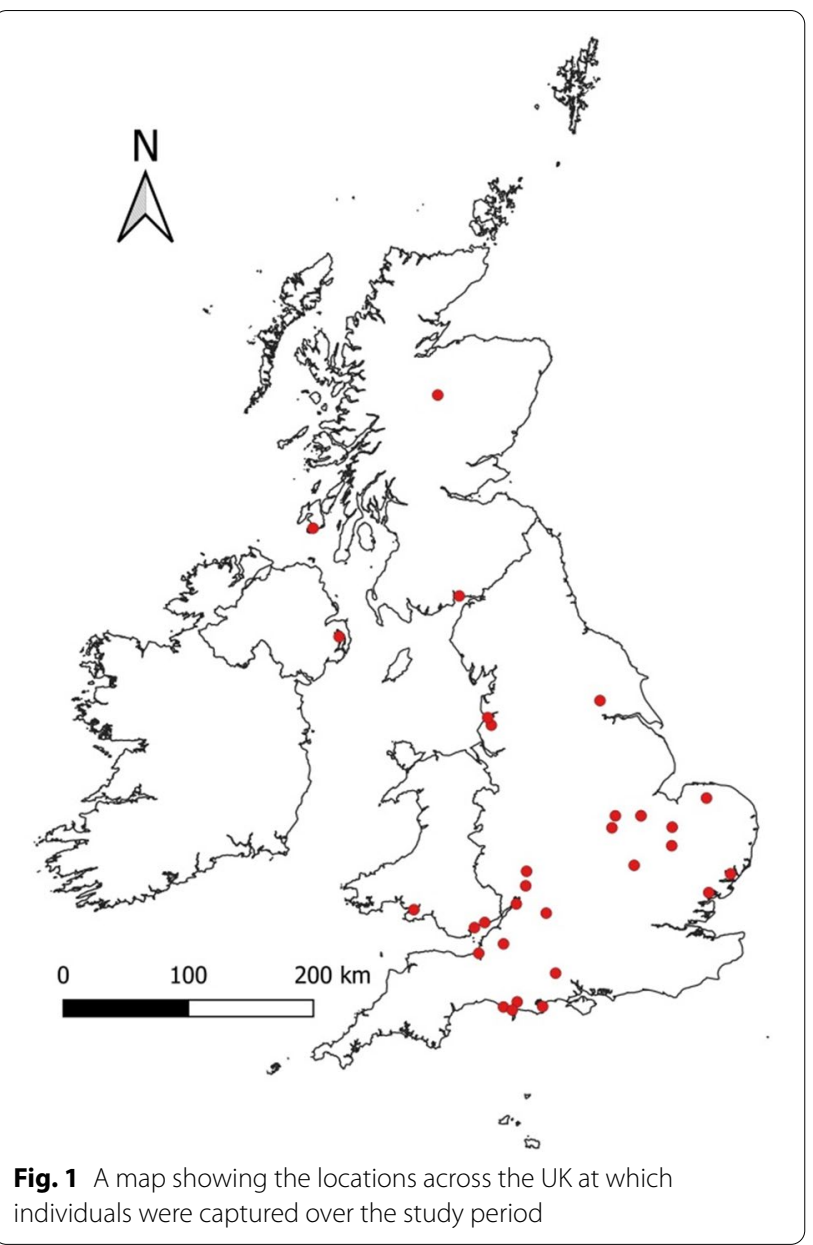

then trapped for capture, as well as cage traps and cannon nets (Scott 1949; Wainwright 1957; Thompson and DeLong 1967). Although these were traditional methods of catching wild ducks, decoys, cage traps and cannon nets have continued to provide a means of capturing ducks and other waterbirds for ringing studies (Mitchell and Ogilvie 1996). The consistency of capture methodology over time provides valuable long-term datasets with which to address ornithological research questions. Additional information on the duck capture methodology has been given by previous authors (e.g. Owen and Cook 1977; Owen and Montgomery 1978; Fox et al. 1992; Mitchell and Ogilvie 1996). Inspection of plumage characteristics and cloacal examinations were used to assess the species identity, age class, and sex of each individual that was captured (Madge and Burn 1988; Carney 1992). European Union for Bird Ringing (EURING) codes 3 and 5 were categorised as first year juveniles, codes 4 and $6+$ were categorised as adults, while the small number of code 2 individuals were removed from our sample as these individuals could not be placed in either category.
Metal leg rings were fitted so that individuals could be identified if recaptured. In total, our data set comprised 91,004 captures of 81,983 unique individual birds of 9 species (Table 1) comprising species of dabbling ducks, diving ducks, and a shelduck: Gadwall (Mareca strepera), Northern Mallard (Anas platyrhynchos), Northern Pintail (Anas acuta), Common Pochard, Common Shelduck (Tadorna tadorna), Northern Shoveler (Spatula clypeata), Eurasian Teal (Anas crecca), Tufted Duck, and Eurasian Wigeon (Additional file 1: Table S1).

\section{Statistical analyses}

All of our statistical analyses were carried out in $R$ version 3.6.3 (R Core Team 2020). Statistically significant results were attributed where $P<0.05$, after all $P$ values had been adjusted using Hommel-Bonferroni corrections to account for multiple comparisons (Hommel 1988). To address our first prediction regarding male bias among our focal populations, we used two-tailed binomial tests to assess whether the species-specific proportions of males among (i) first-winter juveniles, (ii) adults, and (iii) all individuals, showed significant deviations from a 1:1 ratio of males and females. Data were pooled over all winters for each of the binomial tests. Statistically significant male bias in a sex ratio was attributed where the adjusted $P$ value associated with each test was $<0.05$ and the binomial 95\% Confidence Interval (CI) did not span 0.5. Next, to evaluate our second hypothesis, we used a two-sample binomial test for equality of proportions for each of our nine focal species to assess whether the proportions of males among first-winter juveniles differed significantly from the proportions of males among adults, again based on data pooled across all years (Crawley 2005).

To address our third hypothesis regarding differing temporal trends in male bias in adults and first-winter juveniles, we used generalised linear models with binomial error structures to test for a temporal trend in the probability that a captured individual would be a male. Separate models were run for each species. All models were implemented using the lme4 and MuMIn packages in R (Bartoń 2012; Bates et al. 2015). For each set of species-specific models, the response variable was the sex of each captured bird $(0=$ female, $1=$ male $)$. Our 91,004 captures comprised 81,983 unique individuals (mean $\pm \mathrm{SD}$ number of captures per individual $=1.11 \pm 0.51$, range $=1-20 ;$ Additional file 1 : Table S1). Our large sample sizes for our 9 species mean that our conclusions will be robust against such minor pseudoreplication, whilst the advantages of accounting for pseudoreplication via a random effect in a mixed modelling approach would have been outweighed by the considerable additional complexity of a mixed effects model compared with a linear model. We tested three 
Table 1 A summary of the proportion of males $\left(P_{\text {Males }}\right)$ among first-winter juveniles, adults, and all individuals in each species, based on the total numbers of all individuals ( $\left.n_{\text {Total }}\right)$ and the number of males $\left(n_{\text {Males }}\right)$

\begin{tabular}{|c|c|c|c|c|c|}
\hline Species & Age class & $n_{\text {Total }}$ & $n_{\text {Males }}$ & $P_{\text {Males }}$ & $P$ value \\
\hline \multirow[t]{3}{*}{ Gadwall } & First-winter juveniles & 843 & 406 & $0.482(0.447-0.516)$ & 0.603 \\
\hline & Adults & 987 & 624 & $0.632(0.601-0.662)$ & $<0.001$ \\
\hline & All individuals & 1830 & 1030 & $0.563(0.540-0.586)$ & $<0.001$ \\
\hline \multirow[t]{3}{*}{ Northern Mallard } & First-winter juveniles & 15,458 & 8039 & $0.520(0.512-0.528)$ & $<0.001$ \\
\hline & Adults & 14,677 & 9008 & $0.614(0.606-0.622)$ & $<0.001$ \\
\hline & All individuals & 30,135 & 17,047 & $0.566(0.560-0.571)$ & $<0.001$ \\
\hline \multirow[t]{3}{*}{ Northern Pintail } & First-winter juveniles & 1914 & 829 & $0.433(0.411-0.456)$ & $<0.001$ \\
\hline & Adults & 2965 & 2001 & $0.675(0.658-0.692)$ & $<0.001$ \\
\hline & All individuals & 4879 & 2830 & $0.580(0.566-0.594)$ & $<0.001$ \\
\hline \multirow[t]{3}{*}{ Common Pochard } & First-winter juveniles & 1678 & 975 & $0.581(0.557-0.605)$ & $<0.001$ \\
\hline & Adults & 4224 & 3348 & $0.793(0.780-0.805)$ & $<0.001$ \\
\hline & All individuals & 5902 & 4323 & $0.732(0.721-0.744)$ & $<0.001$ \\
\hline \multirow[t]{3}{*}{ Common Shelduck } & First-winter juveniles & 309 & 137 & $0.443(0.387-0.501)$ & 0.159 \\
\hline & Adults & 2743 & 2289 & $0.834(0.820-0.848)$ & $<0.001$ \\
\hline & All individuals & 3052 & 2426 & $0.795(0.780-0.809)$ & $<0.001$ \\
\hline \multirow[t]{3}{*}{ Northern Shoveler } & First-winter juveniles & 194 & 111 & $0.572(0.499-0.643)$ & 0.157 \\
\hline & Adults & 265 & 190 & $0.717(0.659-0.770)$ & $<0.001$ \\
\hline & All individuals & 459 & 301 & $0.656(0.610-0.699)$ & $<0.001$ \\
\hline \multirow[t]{3}{*}{ Eurasian Teal } & First-winter juveniles & 20,828 & 12,363 & $0.594(0.587-0.600)$ & $<0.001$ \\
\hline & Adults & 12,153 & 7354 & $0.605(0.596-0.614)$ & $<0.001$ \\
\hline & All individuals & 32,981 & 19,717 & $0.598(0.593-0.603)$ & $<0.001$ \\
\hline \multirow[t]{3}{*}{ Tufted Duck } & First-winter juveniles & 3989 & 1766 & $0.443(0.427-0.458)$ & $<0.001$ \\
\hline & Adults & 2267 & 1341 & $0.592(0.571-0.612)$ & $<0.001$ \\
\hline & All individuals & 6256 & 3107 & $0.497(0.484-0.509)$ & 0.604 \\
\hline \multirow[t]{3}{*}{ Eurasian Wigeon } & First-winter juveniles & 2796 & 1218 & $0.436(0.417-0.454)$ & $<0.001$ \\
\hline & Adults & 2714 & 1783 & $0.657(0.639-0.675)$ & $<0.001$ \\
\hline & All individuals & 5510 & 3001 & $0.545(0.531-0.558)$ & $<0.001$ \\
\hline
\end{tabular}

Values within parentheses represent the binomial $95 \% \mathrm{Cl}$ for each proportion. The statistical significance of the deviation of each proportion from 0.5 (i.e. parity) is shown

distinct models of temporal variation in male bias, to assess the evidence for linear and non-linear trends, as well as no trend: (i) constant male bias over the study period, (ii) linear trend in male bias over time, and (iii) quadratic trend in male bias over time. These three temporal patterns were mutually exclusive and so were not included in the same candidate model to avoid issues with collinearity (Dormann et al. 2013). In addition to the temporal term alone, we tested each temporal term both with and without the following variables: (i) the age class of the individual (first-winter juvenile or adult), (ii) the latitude of the capture site, and (iii) the number of days after the start of the winter season that the bird was captured. We opted to include either additive or interactive effects of these variables according to whether there was a plausible biological effect in order to reduce the chance of spurious findings; different age classes could have shown similar or divergent temporal trends in male bias (as per our third hypothesis), and so we tested both additive and interactive effects of age class with temporal trends. An additive latitudinal effect was included as sex ratio in some bird species shows a consistent relationship with latitude, with greater proportions of males observed at more northerly sites (Ketterson and Nolan 1976; Alexander 1983; Owen and Dix 1986; Carbone and Owen 1995; Brides et al. 2017). An additive effect of winter date was included as numerous studies have documented that among migratory ducks males often migrate before females (Owen and Mitchell 1988; Mitchell et al. 2008; Guillemain et al. 2013), hence sex ratio in earlier winter months would be expected to show a higher male bias relative to later months (Frew et al. 2018). We confirmed that these covariates were not correlated (tested via Pearson's correlations) for any species-specific dataset; $r< \pm 0.24$ for all species (Additional file 1: Fig. S1), considerably less than the 0.70 threshold at which collinearity is known to affect model estimation and subsequent predictions (Dormann et al. 2013). 
Within the set of candidate models for each species, the model with the lowest second-order Akaike's Information Criteria (AICc) value was judged to be our best-supported model for that species, whilst any model with an AICc value of within 2.0 of the lowest AICc was also judged to have received substantial support in the data (Burnham et al. 2011). However, to avoid selecting models with uninformative parameters, we judged that a model with one additional parameter was competitive only if the associated AICc value was lower than the more parsimonious model (Arnold 2010). To facilitate more detailed comparisons among our candidate models we also calculated the following metrics as indicators of the relative strength of support that each model received in the data: (i) the relative likelihood, representing the probability of that model being the best-fitting model compared with the best-supported model shown by AICc, (ii) the Akaike weight, defined as the ratio of $\triangle \mathrm{AICc}$ values for each model relative to the whole set of candidate models, and (iii) the evidence ratio, representing how many more times less likely to be the best-fitting model compared with the best-supported model shown by AICc (Burnham et al. 2011). We also used Nagelkerke's $R^{2}$ (Nagelkerke 1991) to assess the relative fit of our models, calculated using the DescTools package in R (Signorell 2020). Nagelkerke's $R^{2}$ is an adjusted version of Cox and Snell's $R^{2}$ (Cox and Snell 1989) that corrects the scale of the statistic to span the full theoretical range from 0.0 to 1.0 where model covariates might include categorical variables. However, as with all pseudo $R^{2}$ metrics, in practice Nagelkerke's $R^{2}$ values typically appear very low relative to a "true $R^{2}$ ", even where model fit is excellent (Signorell 2020). Therefore, we use this metric with caution by focusing on the relative differences in $R^{2}$ values between competing models, rather than on the absolute $R^{2}$ values themselves as a measure of explanatory power.

\section{Results}

\section{Gadwall}

The proportion of males among all 1830 Gadwall captured over the study period was 0.563 (binomial 95\% $\mathrm{CI}=0.540-0.586$ ), which represented a significantly male-biased sex ratio (Table 1; Fig. 2). While the proportion of males among adults was $0.632(0.601-0.662)$ and hence also showed a male-bias, among first-winter juveniles the sex ratio did not differ from parity, with a proportion of males of 0.482 (0.447-0.516) (Table 1; Fig. 3a). The proportion of males among adults was therefore significantly greater than among first-winter juveniles (Table 2).

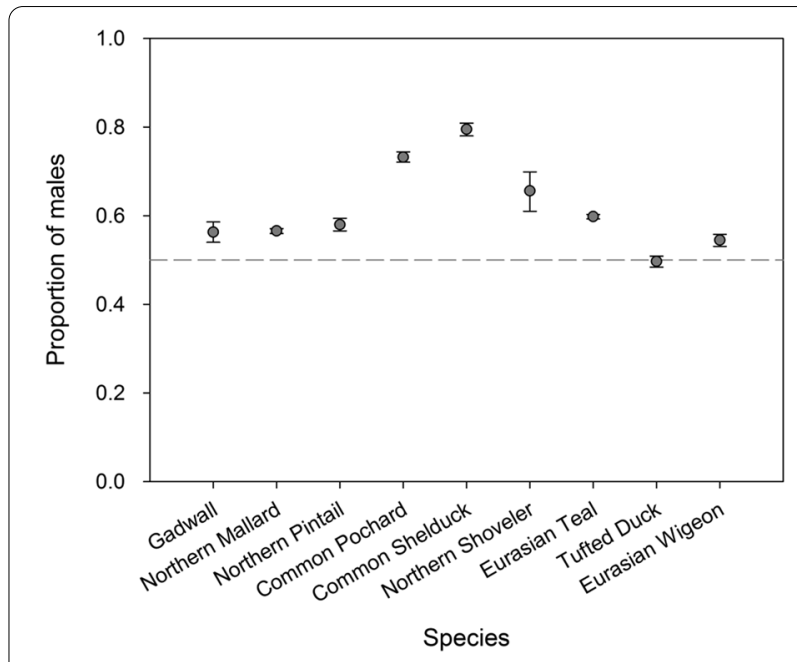

Fig. 2 The proportion of males among all individuals for each species. The error bars represent the binomial 95\% Cl associated with each proportion, while the grey dashed line indicates parity (i.e. a 0.5 proportion of males)

A comparison of all candidate models of betweenindividual variation in the probability of a captured Gadwall being male, revealed that four models had associated $\triangle \mathrm{AICC}$ values of $<2.0$, and hence were potentially competitive (Table 3 ; Additional file 1: Table S2a). The model with the lowest AICc value was comprised of an intercept and the age class, and accounted for $29.2 \%$ of the total Akaike weights of the set of candidate models. The other three models with $\triangle \mathrm{AICc}$ values of $<2.0$ were all more complex versions of this model, i.e. all contained the intercept, age class and an additional parameter. Given that the additions of these parameters increased rather than reduced the AICc value, and had only marginal effects on Nagelkerke's $R^{2}$ values ( $\leq 0.01$ in all cases), these parameters are likely to have been uninformative (Table 3 ). On this basis, the model containing the intercept and age class was considered our best-supported model.

The predicted estimates associated with this bestsupported model indicated that the probability that a captured individual would be a male was consistently higher for adults than first-winter juveniles (Fig. 4a; Additional file 1: Table S3). However, there was no support for either linear or quadratic trends in male bias, with the best-supported model predicting a constant probability over time of capturing a male Gadwall (Fig. 4a); the model predicted mean $( \pm 95 \% \mathrm{CI})$ male bias probabilities of $0.632(0.603-0.661)$ for adults and $0.482(0.449-0.515)$ for first-winter juveniles, which closely matched the male bias calculated from the raw numbers of males and females (Table 1). 

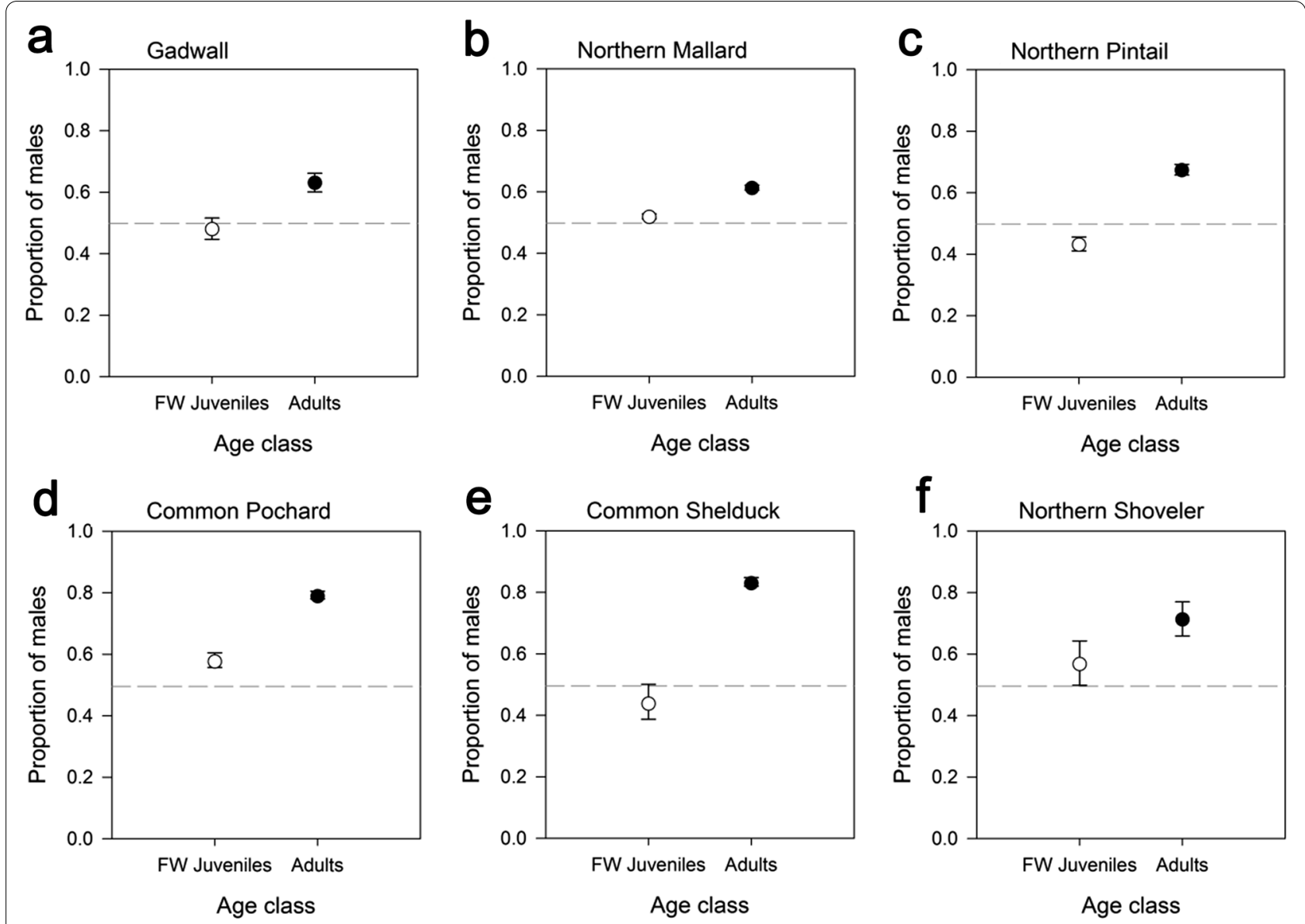

Age class
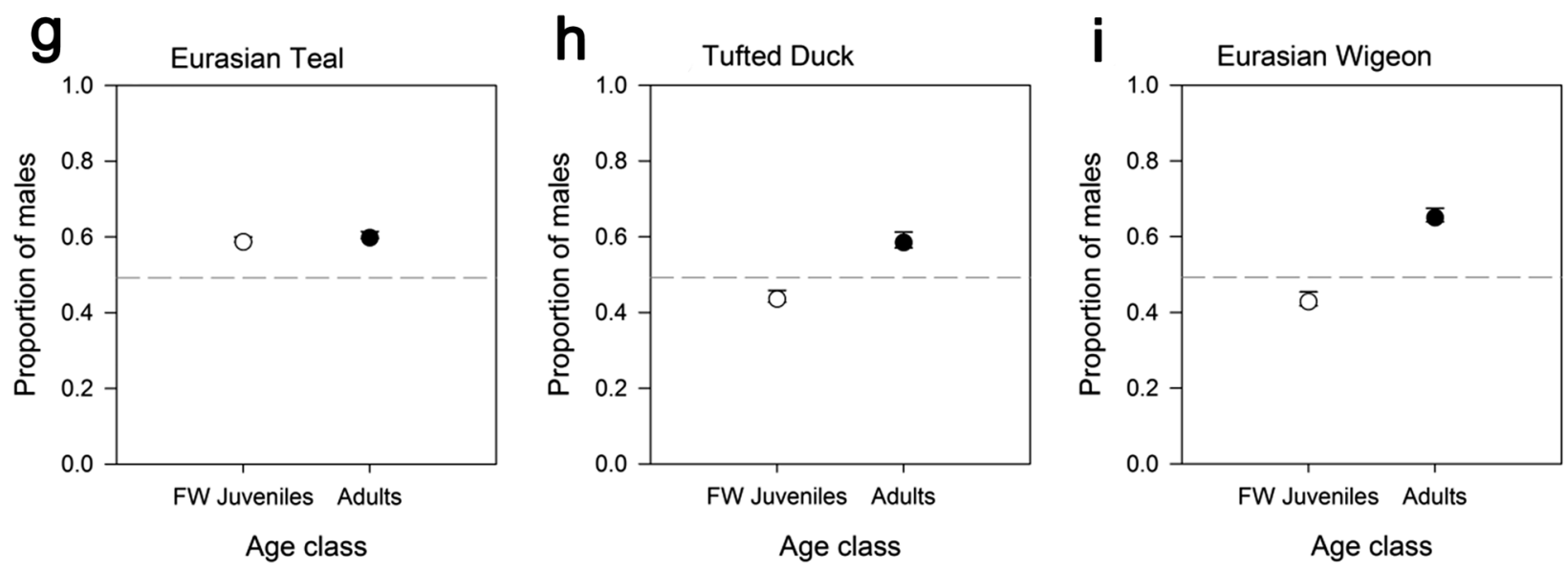

Fig. 3 A comparison of the proportions of males among first-winter juveniles and adults within each species. The error bars represent the binomial $95 \% \mathrm{Cl}$ associated with each proportion, while the grey dashed line indicates parity (i.e. a 0.5 proportion of males). Significant differences between age classes were detected for all species

\section{Northern Mallard}

Among all 30,135 Northern Mallard the proportion males captured was 0.566 (binomial 95\% CI $=0.560-$ 0.571 ), which indicated a significant male-bias in the sex ratio (Table 1; Fig. 2). Similarly, the proportion of males was $0.614(0.606-0.622)$ among adults and was 0.520 (0.512-0.528) among first-winter juveniles, both of which differed significantly from parity (Table 1; Fig. 3b). However, the proportion of males among adults was significantly greater than among first-winter juveniles (Table 2). 
Table 2 The statistical significances of the differences in the proportions of males $\left(P_{\text {Males }}\right)$ among first-winter juveniles and adults in each species

\begin{tabular}{lccrrr}
\hline Species & FW Juvenile $\boldsymbol{P}_{\text {Males }}$ & Adult $\boldsymbol{P}_{\text {Males }}$ & $\boldsymbol{t}$ & $\boldsymbol{X}^{\mathbf{2}}$ & $\boldsymbol{P}$ value \\
\hline Gadwall & $0.482(0.447-0.516)$ & $0.632(0.601-0.662)$ & 6.4 & 41.3 & $<0.001$ \\
Northern Mallard & $0.520(0.512-0.528)$ & $0.614(0.606-0.622)$ & 16.4 & 268.6 & $<0.001$ \\
Northern Pintail & $0.433(0.411-0.456)$ & $0.675(0.658-0.692)$ & 16.7 & 278.1 & $<0.001$ \\
Common Pochard & $0.581(0.557-0.605)$ & $0.793(0.780-0.805)$ & 16.5 & 273.2 & $<0.001$ \\
Common Shelduck & $0.443(0.387-0.501)$ & $0.834(0.820-0.848)$ & 16.1 & 3.1 & 258.2 \\
Northern Shoveler & $0.572(0.499-0.643)$ & $0.717(0.659-0.770)$ & 2.0 & 9.8 & 0.001 \\
Eurasian Teal & $0.594(0.587-0.600)$ & $0.605(0.596-0.614)$ & 11.3 & 127.5 & 0.040 \\
Tufted Duck & $0.443(0.427-0.458)$ & $0.592(0.571-0.612)$ & 16.5 & 271.2 & $<0.001$ \\
Eurasian Wigeon & $0.436(0.417-0.454)$ & $0.657(0.639-0.675)$ & $<0.001$ \\
\hline
\end{tabular}

Based on data for the entire study period of winters 1963/64-2019/20. Values within parentheses represent the binomial 95\% Cl for each proportion

Within our set of candidate models of between-individual variation in the probability of a captured Northern Mallard being male, only two models had associated $\triangle \mathrm{AICc}$ values of $<2.0$, and hence were potentially competitive (Table 3; Additional file 1: Table S2b). The first of these models, with the lowest absolute AICc value, featured an intercept, the age class of the individuals, the winter date on which the individual was captured, as well as a quadratic temporal trend (Table 3). This model accounted for $62.7 \%$ of the total Akaike weights of the set of candidate models (Table 3). The second model contained all of the parameters in the first, as well as the latitude of the capture site; however, this second model was only marginally within the 2.0 threshold for consideration as a competitive model $(\triangle \mathrm{AICc}=1.99)$ and accounted for only $23.2 \%$ of the total Akaike weights of the set of candidate models (Table 3). Moreover, as the second model was a more complex version of the first model, but achieved a higher AICc value and equivalent Nagelkerke's $R^{2}$ value, we considered the latitude parameter to have been uninformative. Therefore, the best-supported model was considered to have been the first.

The interaction between the quadratic temporal trend and age class in our best-supported model indicated that adults and first-winter juveniles showed different nonlinear temporal trends in male bias (Additional file 1: Table S3). The model also indicated a small but positive effect of winter date, such that the probability that a captured individual would be male increased over the course of the winter (Additional file 1: Table S3); subsequent model predictions were made for the mean winter date of 102 days, to allow variation between winters and between age classes to be assessed. The predicted mean $( \pm 95 \% \mathrm{CI})$ probabilities that a captured Northern Mallard would be male increased among adults from 0.371 (0.348-0.395) in winter $1963 / 64$ up to a high of 0.716 (0.702-0.729) in 2009/10, before showing a marginal decline to 0.701 (0.675-0.727) in 2019/20 (Fig. 4b). In contrast, the predicted probabilities for juveniles showed a strong decrease in male bias over most of the study, declining from $0.603(0.577-0.628)$ in $1963 / 64$ to 0.484 (0.466-0.502) in 2008/09, with a slight increase thereafter to $0.491(0.455-0.527)$ in $2019 / 20$ (Fig. 4b).

\section{Northern Pintail}

The proportion of males among all of our 4879 captured Northern Pintail was 0.580 (binomial 95\% CI $=0.566$ 0.594), which demonstrated significant male-bias among the total sample of birds (Table 1; Fig. 2). However, the proportion of males differed significantly between adults and first-winter juveniles (Table 2; Fig. 3c). Indeed, only the sex ratio of the adult individuals showed male bias, with the proportion of males among adults calculated to be $0.675(0.658-0.692)$. In contrast, the sex ratio among first-winter juveniles was female-biased, with a proportion of males of 0.433 (0.411-0.456) (Table 1).

Among the candidate models of between-individual variation in the probability of a captured Northern Pintail being male, only two models had associated $\triangle \mathrm{AICc}$ values of $<2.0$, and hence could be considered to be potentially competitive (Table 3 ; Additional file 1 : Table S2c). The first of these models, with the lowest absolute AICc value, featured an intercept, the age class of the individuals, the winter date on which the individual was captured, as well as a quadratic temporal trend (Table 3). This model accounted for a total of $48.3 \%$ of the Akaike weights among our candidate models (Table 3; Additional file 1: Table S2c). The second model contained all of the parameters in the first, as well as the latitude of the capture site; however, despite the additional parameter this second model had an associated $\triangle$ AICc value of 1.60 and accounted for only $21.7 \%$ of the total Akaike weights (Table 3; Additional file 1: Table S2c). As the second model was a more complex 
Table 3 The best-supported $(\triangle \mathrm{AIC}<2.0)$ candidate models of the between-individual variation in the probability that a captured bird would be male

\begin{tabular}{|c|c|c|c|c|c|c|c|}
\hline Species & Model & AICc & $\Delta \mathrm{AICC}$ & $\begin{array}{l}\text { Relative } \\
\text { likelihood }\end{array}$ & Akaike weights & Evidence ratio & Nagelkerke's $R^{2}$ \\
\hline \multirow[t]{5}{*}{ Gadwall } & $i+A$ & 2469.94 & 0.00 & 1.00 & 0.292 & 1.00 & 0.030 \\
\hline & $i+A+N$ & 2471.45 & 1.51 & 0.47 & 0.137 & 2.13 & 0.031 \\
\hline & $i+W_{\mathrm{L}}+A$ & 2471.61 & 1.67 & 0.43 & 0.127 & 2.30 & 0.031 \\
\hline & $i+A+D$ & 2471.89 & 1.95 & 0.38 & 0.110 & 2.66 & 0.030 \\
\hline & $i$ & 2509.94 & 40.00 & 0.00 & 0.000 & $4.85 \times 10^{8}$ & 0.000 \\
\hline \multirow[t]{3}{*}{ Northern Mallard } & $i+\left(W_{\mathrm{L}}+W_{\mathrm{Q}}\right)+A+\left(\left(W_{\mathrm{L}}+W_{\mathrm{Q}}\right): A\right)+D$ & $40,345.28$ & 0.00 & 1.00 & 0.627 & 1.00 & 0.041 \\
\hline & $\begin{array}{l}i+\left(W_{\mathrm{L}}+W_{\mathrm{Q}}\right)+A+\left(\left(W_{\mathrm{L}}+W_{\mathrm{Q}}\right): A\right)+N \\
+D\end{array}$ & $40,347.27$ & 1.99 & 0.37 & 0.232 & 2.70 & 0.041 \\
\hline & $i$ & $41,256.36$ & 911.08 & 0.00 & 0.000 & $6.89 \times 10^{197}$ & 0.000 \\
\hline \multirow[t]{3}{*}{ Northern Pintail } & $i+\left(W_{\mathrm{L}}+W_{\mathrm{Q}}\right)+A+\left(\left(W_{\mathrm{L}}+W_{\mathrm{Q}}\right): A\right)+D$ & 6331.82 & 0.00 & 1.00 & 0.483 & 1.00 & 0.085 \\
\hline & $\begin{array}{l}i+\left(W_{\mathrm{L}}+W_{\mathrm{Q}}\right)+A+\left(\left(W_{\mathrm{L}}+W_{\mathrm{Q}}\right): A\right)+N \\
+D\end{array}$ & 6333.43 & 1.60 & 0.45 & 0.217 & 2.23 & 0.086 \\
\hline & i & 6640.17 & 308.35 & 0.00 & 0.000 & $9.06 \times 10^{66}$ & 0.000 \\
\hline \multirow[t]{2}{*}{ Common Pochard } & $i+W_{\mathrm{L}}+A+\left(W_{\mathrm{L}}: A\right)+N+D$ & 6495.44 & 0.00 & 1.00 & 0.796 & 1.00 & 0.089 \\
\hline & i & 6857.68 & 362.24 & 0.00 & 0.000 & $4.57 \times 10^{78}$ & 0.000 \\
\hline \multirow[t]{7}{*}{ Common Shelduck } & $i+W_{\mathrm{L}}+A+\left(W_{\mathrm{L}}: A\right)+N$ & 2878.22 & 0.00 & 1.00 & 0.170 & 1.00 & 0.113 \\
\hline & $i+W_{\mathrm{L}}+A+N$ & 2878.39 & 0.17 & 0.92 & 0.157 & 1.09 & 0.112 \\
\hline & $i+W_{\mathrm{L}}+A+\left(W_{\mathrm{L}}: A\right)$ & 2879.06 & 0.84 & 0.66 & 0.112 & 1.52 & 0.112 \\
\hline & $i+W_{\mathrm{L}}+A$ & 2879.71 & 1.49 & 0.48 & 0.081 & 2.10 & 0.111 \\
\hline & $i+\left(W_{L}+W_{Q}\right)+A+N$ & 2879.88 & 1.66 & 0.44 & 0.074 & 2.29 & 0.113 \\
\hline & $i+W_{\mathrm{L}}+A+\left(W_{\mathrm{L}}: A\right)+N+D$ & 2880.18 & 1.96 & 0.38 & 0.064 & 2.66 & 0.113 \\
\hline & i & 3099.22 & 220.99 & 0.00 & 0.000 & $9.73 \times 19^{47}$ & 0.000 \\
\hline \multirow[t]{7}{*}{ Northern Shoveler } & $i+W_{\mathrm{L}}+A$ & 583.31 & 0.00 & 1.00 & 0.185 & 1.00 & 0.041 \\
\hline & $i+W_{\mathrm{L}}+A+\left(W_{\mathrm{L}}: A\right)$ & 584.52 & 1.21 & 0.55 & 0.101 & 1.83 & 0.043 \\
\hline & $i+A$ & 584.68 & 1.36 & 0.51 & 0.094 & 1.98 & 0.031 \\
\hline & $i+\left(W_{\mathrm{L}}+W_{\mathrm{Q}}\right)+A$ & 585.01 & 1.70 & 0.43 & 0.079 & 2.34 & 0.042 \\
\hline & $i+W_{L}+A+D$ & 585.14 & 1.82 & 0.40 & 0.074 & 2.49 & 0.041 \\
\hline & $i+W_{\mathrm{L}}+A+N$ & 585.31 & 1.99 & 0.37 & 0.068 & 2.71 & 0.041 \\
\hline & i & 593.02 & 9.70 & 0.01 & 0.001 & 127.94 & 0.000 \\
\hline \multirow[t]{2}{*}{ Eurasian Teal } & $\begin{array}{l}i+\left(W_{\mathrm{L}}+W_{\mathrm{Q}}\right)+A+\left(\left(W_{\mathrm{L}}+W_{\mathrm{Q}}\right): A\right)+ \\
N+D\end{array}$ & $44,224.58$ & 0.00 & 1.00 & 0.907 & 1.00 & 0.010 \\
\hline & i & $44,452.61$ & 228.03 & 0.00 & 0.000 & $3.28 \times 10^{49}$ & 0.000 \\
\hline \multirow[t]{3}{*}{ Tufted Duck } & $i+W_{\mathrm{L}}+A+\left(W_{\mathrm{L}}: A\right)+N+D$ & 8450.02 & 0.00 & 1.00 & 0.554 & 1.00 & 0.049 \\
\hline & $\begin{array}{l}i+\left(W_{\mathrm{L}}+W_{\mathrm{Q}}\right)+A+\left(\left(W_{\mathrm{L}}+W_{\mathrm{Q}}\right): A\right)+N \\
+D\end{array}$ & 8450.46 & 0.44 & 0.80 & 0.445 & 1.25 & 0.050 \\
\hline & i & 8674.38 & 224.36 & 0.00 & 0.000 & $5.23 \times 10^{48}$ & 0.000 \\
\hline \multirow[t]{2}{*}{ Eurasian Wigeon } & $\begin{array}{l}i+\left(W_{\mathrm{L}}+W_{\mathrm{Q}}\right)+A+\left(\left(W_{\mathrm{L}}+W_{\mathrm{Q}}\right): A\right)+ \\
N+D\end{array}$ & 7270.31 & 0.00 & 1.00 & 0.867 & 1.00 & 0.080 \\
\hline & i & 7596.49 & 326.18 & 0.00 & 0.000 & $6.74 \times 10^{70}$ & 0.000 \\
\hline
\end{tabular}

The null model, comprised of the intercept alone, is also included for each species for comparison. The lowest AICc model for each species is indicated in bold. Full model comparison for each species is given in Additional file 1: Tables S2a-i. Parameters: $i=$ intercept, $W_{\mathrm{L}}=$ linear trend over winters, $W_{\mathrm{Q}}=$ quadratic trend over winters, $A_{\jmath}=$ age class (juveniles), $D=$ winter date, $N=$ latitude

version of the first model, but achieved a higher AICc value and equivalent Nagelkerke's $R^{2}$ value, we considered the latitude parameter to have been uninformative. Therefore, the first model was considered to have been the best-supported among all candidate models.
The interaction between the quadratic temporal trend and age class in our best-supported model indicated that adult and first-winter juvenile Northern Pintails showed divergent trends in male bias (Additional file 1: Table S3). The probability that a captured individual would be male 

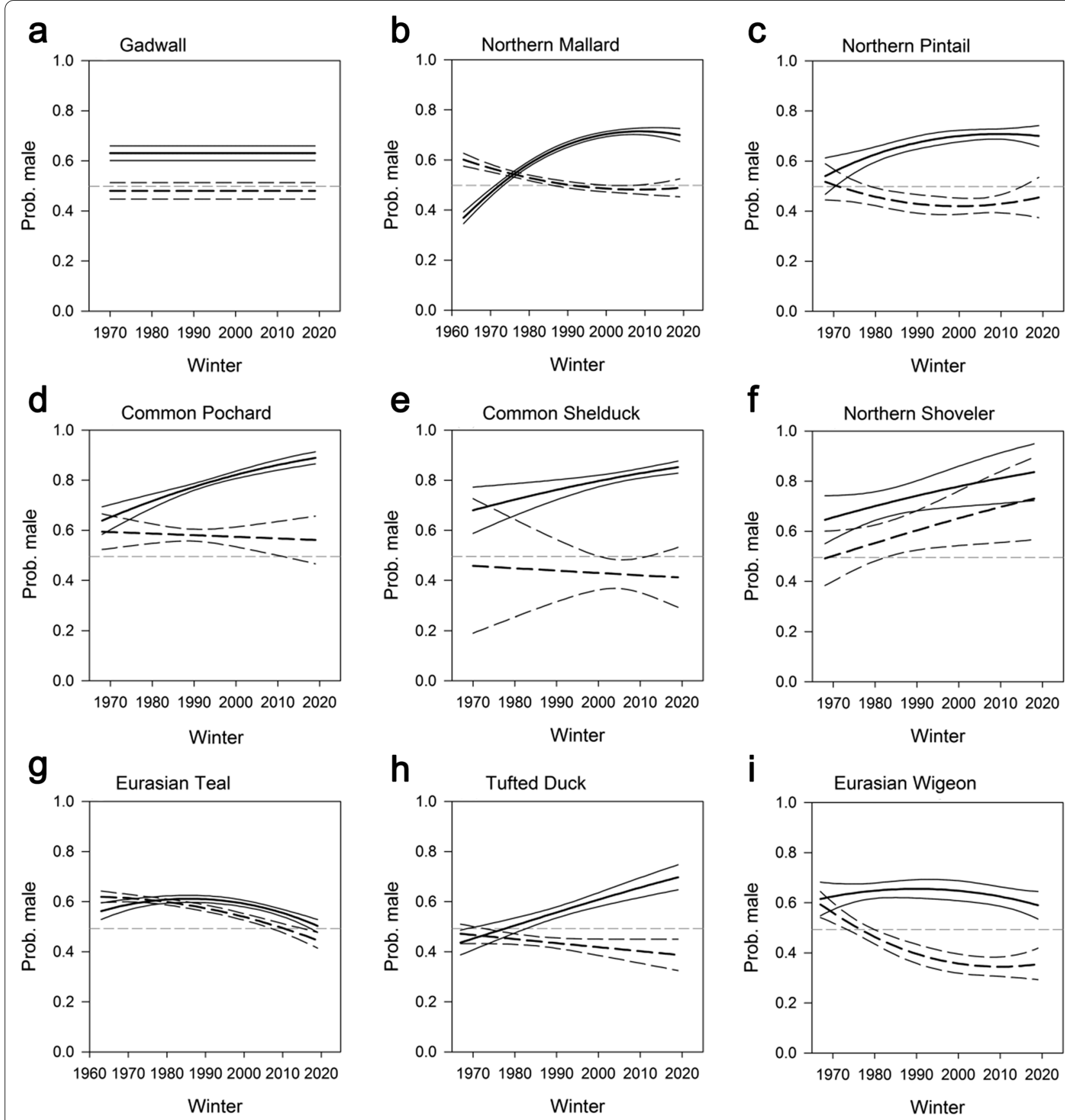

\section{- Adults - - FW Juveniles}

Fig. 4 The estimated temporal trends in the probability that a captured individual would be a male, among adults (solid black lines) and first-winter juveniles (dashed black lines), based on the mean ( $\pm 95 \% \mathrm{Cl}$ ) predictions of our best-supported model for each species. The grey dashed line indicates a 0.5 probability of a male

also increased over the course of the winter (Additional file 1: Table S3); subsequent model predictions were made for the mean winter date of 102 days, to allow variation between winters and between age classes to be assessed.
The predicted mean $( \pm 95 \% \mathrm{CI})$ probabilities that a captured Northern Pintail would be male increased among adults from $0.542(0.469-0.614)$ in winter $1968 / 69$ up to a peak of $0.709(0.689-0.730)$ in $2010 / 11$, before showing 
a marginal decline to $0.702(0.660-0.743)$ in $2019 / 20$ (Fig. 4c). The predicted probabilities for juveniles showed a different trend, with a decrease in male bias from 0.519 $(0.447-0.591)$ in $1968 / 69$ to a low of $0.422(0.390-0.454)$ in 2000/01, with a marginal increase thereafter to 0.457 (0.376-0.537) in 2019/20 (Fig. 4c).

\section{Common Pochard}

The proportion of male Common Pochard in our total sample of 5902 captured individuals was 0.732 (binomial $95 \% \mathrm{CI}=0.721-0.744$ ), which illustrated a significantly male-biased sex ratio (Table 1; Fig. 2). The proportion of males among first-winter juveniles was 0.581 (0.557$0.605)$, which was somewhat lower than the proportion of $0.793(0.780-0.805)$ recorded among adults (Table 1; Fig. 3d); a binomial test demonstrated that this difference in the proportion of males between adults and first-winter juveniles was statistically significant (Table 2).

In our set of candidate models of between-individual variation in the probability that a captured Common Pochard was male, only one model had associated $\triangle \mathrm{AICc}$ values of $<2.0$, and thus could be considered to be potentially competitive (Table 3; Additional file 1: Table S2d). This model had a linear effect of time, together with an intercept, an effect of age, latitude, and winter date (Additional file 1: Table S3). The model accounted for $79.3 \%$ of the total Akaike weights, and was thus considered to be our best-supported model.

The interaction between the linear temporal trend and age class in our best-supported model indicated differing trends in male bias between adult and first-winter juvenile Common Pochard (Additional file 1: Table S3). The probability that a captured individual would be male also increased over the course of the winter and with latitude (Additional file 1: Table S3); subsequent model predictions were made for the mean winter date of 102 days and for a mean latitude of 52.1 decimal degrees, to allow variation between winters and between age classes to be assessed. The predicted mean $( \pm 95 \% \mathrm{CI})$ probabilities that a captured Common Pochard would be male showed a sustained increase over the study period among adults from $0.643(0.588-0.698)$ in winter $1968 / 69$ up to 0.893 (0.869-0.917) in 2019/20 (Fig. 4d). No such increase was evident for the first-winter juvenile Common Pochard, for which a marginal decline in male bias was predicted, falling from $0.599(0.528-0.670)$ in $1968 / 69$ to 0.566 (0.471-0.661) in 2019/20 (Fig. 4d).

\section{Common Shelduck}

The proportion of males among our total sample of 3052 Common Shelduck was 0.795 (binomial 95\% CI $=0.780$ 0.809 ), which was the most male-biased sex ratio of recorded for any of our 9 focal species (Table 1; Fig. 2).
An examination of the first-winter juveniles only, however, indicated that the proportion of males was 0.443 (0.387-0.501); however, based on the $P$ values associated with our binomial test, the female bias among juvenile Common Shelducks was not statistically significant. In contrast, among the sample of adult individuals the proportion of males of $0.834(0.820-0.848)$ was significantly male-biased (Table 1; Fig. 3e). The proportion of males among adults was therefore significantly greater than among first-winter juveniles (Table 2).

A comparison of all candidate models of between-individual variation in the probability of a captured Common Shelduck being male, revealed that six models had associated $\triangle \mathrm{AICc}$ values of $<2.0$, and hence were potentially competitive (Table 3; Additional file 1: Table S2e). Our best-supported model was comprised of an intercept, an interaction between a linear effect of time and age class, as well as an effect of latitude (Table 3; Additional file 1: Table S3). Although the Akaike weight associated with this best-supported model (17.0\%) was relatively low compared with most of the other species (Table 3), this model had an improved Nagelkerke's $R^{2}$ and lower $\triangle$ AICc value compared with all other models including a simpler version of this model, which suggested that these effects were important (Table 3 ).

The interaction between the linear temporal trend and age class in our best-supported model indicated differing trends in male bias between adult and first-winter juvenile Common Shelduck (Additional file 1: Table S3). The probability that a captured individual would be male increased with latitude and hence subsequent model predictions were made for a mean latitude of 52.1 decimal degrees, to allow variation between winters and between age classes to be assessed. The predicted mean $( \pm 95 \%$ CI $)$ probabilities that a captured Common Shelduck would be male showed a sustained increase over the study period among adults from $0.684(0.592-0.776)$ in winter $1970 / 71$ up to $0.856(0.832-0.880)$ in $2019 / 20$ (Fig. 4e). In contrast, there was some evidence of a temporal decline in male bias among the first-winter juvenile Common Shelduck, for which the probability of being male declined from $0.463(0.195-0.731)$ in $1970 / 71$ to 0.417 (0.297-0.537) in 2019/20 (Fig. 4e); however, the relatively low sample size obtained for Common Shelduck meant that the confidence intervals associated with these estimates were large, and hence certainty in the trend for first-winter juveniles was low (Table 1; Fig. 4e).

\section{Northern Shoveler}

The proportion of males among all 459 Northern Shoveler was 0.656 (binomial $95 \% \mathrm{CI}=0.610-0.699$ ), indicative of a significantly male-biased sex ratio (Table 1; Fig. 2). The proportion of males among adults was 0.717 
(0.659-0.770) and hence also showed a clear male-bias. The male-bias among the first-winter juveniles the sex ratio was less pronounced, with a proportion of males of $0.572(0.499-0.643)$ which was not statistically significantly different from parity (Table 1; Fig. 3f). The proportion of males among the adults was therefore found to be significantly greater than among the first-winter juveniles (Table 2).

Among all candidate models of between-individual variation in the probability that a captured Northern Shoveler was male, a total of six models had associated $\triangle$ AICc values of $<2.0$, and hence were potentially competitive (Table 3; Additional file 1: Table S2f). Our best-supported model was comprised of an intercept, age class, and a linear effect of time (Table 3; Additional file 1: Table S3). Although the Akaike weight associated with this best-supported model $(18.5 \%)$ was relatively low compared with most of the other species (Table 3), this model had an improved Nagelkerke's $R^{2}$ and lower $\triangle A I C c$ value compared with a simpler version of this model (which lacked the linear temporal trend), which suggested that the linear effect of time was important (Table 3). The remaining five models within $\triangle \mathrm{AICc}<2.0$ were all more complex versions of our best-supported model, as they contained the same parameters in addition to at least one other parameter, but all had higher AICc values which suggested that the additional parameters were uninformative (Table 3 ).

The predicted mean $( \pm 95 \% \mathrm{CI})$ probabilities that a captured Northern Shoveler would be male showed a linear increase over the study period among adults from 0.650 (0.555-0.746) in winter $1968 / 69$ up to 0.840 (0.7270.953) in 2019/20 (Fig. 4f; Additional file 1: Table S3). The probability also increased among first-winter juvenile Northern Shoveler, from 0.496 (0.388-0.605) in 1968/69 to 0.735 (0.571-0.899) in $2019 / 20$ (Fig. 4f); however, the relatively low sample size obtained for first-winter juvenile Northern Shoveler (Table 1) meant that the confidence intervals, and hence the uncertainty, associated with these estimates were large (Fig. 4f).

\section{Eurasian Teal}

Among all 32,981 Eurasian Teal the proportion males captured was 0.598 (binomial 95\% CI $=0.593-0.603$ ), consistent with a male-biased sex ratio (Table 1; Fig. 2). Similarly, the proportion of males was 0.605 (0.596$0.614)$ among adults and $0.594(0.587-0.600)$ among first-winter juveniles, both of which also differed significantly from parity (Table 1; Fig. 3g). The difference in the proportions of males among adults and first-winter juveniles, while statistically significant, was the smallest difference recorded for any of our focal species (Table 2).
In our set of candidate models of between-individual variation in the probability that a captured Eurasian Teal was male, only one model had associated $\triangle$ AICc values of $<2.0$, and thus could be considered to be potentially competitive (Table 3; Additional file 1: Table S2g). This model, which accounted for $90.7 \%$ of the total Akaike weights, comprised an intercept, effects of both latitude and winter date, together with an interaction between age class and a quadratic temporal trend (Additional file 1: Table S3). The model was thus considered to be our best-supported model.

The interaction between the quadratic temporal trend and age class in our best-supported model indicated that adult and first-winter juvenile Eurasian Teal showed divergent non-linear trends in male bias (Additional file 1: Table S3). The probability that a captured individual would be male decreased over the course of the winter and increased with latitude (Additional file 1: Table S3); subsequent model predictions were therefore made for the mean winter date of 102 days and for a mean latitude of 52.1 decimal degrees, to allow variation between winters and between age classes to be assessed. The predicted mean $( \pm 95 \% \mathrm{CI})$ probabilities that a captured Eurasian Teal would be male increased among adults from $0.569(0.536-0.602)$ in winter $1963 / 64$ up to a peak of $0.618(0.604-0.632)$ in 1986/87, before undergoing a decline thereafter to $0.510(0.485-0.536)$ in $2019 / 20$ (Fig. 4g). Among first-winter juvenile Eurasian Teal, male bias was predicted to undergo a temporal decline, the slope of which accelerated over the study period, falling from $0.626(0.603-0.649)$ in $1963 / 64$ to $0.453(0.421-$ 0.484 ) in $2019 / 20$ (Fig. 4g).

\section{Tufted Duck}

The proportion of males within our total sample of 6256 Tufted Duck was 0.497 (binomial 95\% CI $=0.484-0.509$ ), which made Tufted Duck the only one of our 9 focal species to have a sex ratio for all individuals that was not male-biased and did not differ significantly from parity (Table 1; Fig. 2). While the proportion of males among first-winter juveniles was $0.443(0.427-0.458)$ indicating a female bias, among adults the sex ratio was significantly male-biased, with a proportion of males of 0.592 (0.5710.612) (Table 1; Fig. 3h). The proportion of males among adults was therefore significantly greater than among first-winter juveniles (Table 2).

Within the set of candidate models of between-individual variation in the probability that a captured Tufted Duck was male, only two models had associated $\triangle \mathrm{AICc}$ values of $<2.0$, and thus could be considered to be potentially competitive (Table 3; Additional file 1: Table S2h). The model with the lowest absolute AICc value featured an intercept, effects of both latitude and winter date, 
as well as an interaction between age class and a linear temporal trend (Table 3). The second model was a more complex version containing the same parameters with the exception of a quadratic, rather than linear, temporal trend (Table 3). The linear trend model accounted for $55.4 \%$ of the total Akaike weights, compared with $44.5 \%$ for the quadratic trend. In addition to the lower Akaike weight and higher AICc value, the addition of the quadratic parameter made only a negligible improvement of 0.0008 to Nagelkerke's $R^{2}$, which suggests little support for the quadratic trend (Table 3 ). The model containing the linear, rather than quadratic, trend was therefore considered to be our best-supported model.

The interaction between the linear temporal trend and age class in our best-supported model indicated differing trends in male bias between adult and first-winter juvenile Tufted Duck (Additional file 1: Table S3). The probability that a captured individual would be male decreased over the course of the winter and increased with latitude (Additional file 1: Table S3); subsequent model predictions were made for the mean winter date of 102 days and for a mean latitude of 52.1 decimal degrees, to allow variation between winters and between age classes to be assessed. The predicted mean $( \pm 95 \% \mathrm{CI})$ probabilities that a captured Tufted Duck would be male showed a sustained increase over the study period among adults from $0.444(0.395-0.493)$ in winter $1967 / 68$ up to 0.704 (0.654-0.754) in 2019/20 (Fig. 4h). No such increase was evident among the first-winter juvenile Tufted Duck, which showed a decline in the probability that a captured individual would be male, from $0.479(0.440-0.517)$ in $1967 / 68$ to $0.395(0.332-0.457)$ in $2019 / 20$ (Fig. 4h).

\section{Eurasian Wigeon}

The proportion of males among our total sample of 5510 Eurasian Wigeon was 0.545 (binomial 95\% CI $=0.531-$ 0.558), which demonstrated significant male-bias among the total sample of birds (Table 1; Fig. 2). However, the proportion of males differed significantly between adults and first-winter juveniles (Table 2; Fig. 3i). Indeed, only the sex ratio of the adult individuals showed male bias, with the proportion of males among adults calculated to be $0.657(0.639-0.675)$. In contrast, the sex ratio among first-winter juveniles was female-biased, with a proportion of males of $0.436(0.417-0.454)$ (Table 1$)$.

In our set of candidate models of between-individual variation in the probability that a captured Eurasian Wigeon was male, only one model had associated $\triangle \mathrm{AICC}$ values of $<2.0$, and was thus considered to be our bestsupported model (Table 3; Additional file 1: Table S2i). This model, which accounted for $86.7 \%$ of the total Akaike weights, featured an intercept, effects of both latitude and winter date, together with an interaction between age class and a quadratic temporal trend (Additional file 1: Table S3).

The interaction between the quadratic temporal trend and age class in our best-supported model indicated that adult and first-winter juvenile Eurasian Wigeon showed divergent non-linear trends in male bias (Additional file 1: Table S3). The probability that a captured individual would be male increased over the course of the winter and also with latitude (Additional file 1: Table S3); subsequent model predictions were therefore made for the mean winter date of 102 days and for a mean capture site latitude of 52.1 decimal degrees, to allow variation between winters and between age classes to be assessed. The predicted mean $( \pm 95 \% \mathrm{CI})$ probabilities that a captured Eurasian Wigeon would be male increased among adults from $0.622(0.555-0.689)$ in winter $1967 / 68$ up to a peak of $0.662(0.625-0.699)$ in $1990 / 91$, before declining thereafter to $0.597(0.542-0.652)$ in $2019 / 20$ (Fig. 4i). Among first-winter juvenile Eurasian Wigeon, male bias was predicted to undergo a substantial temporal decline, from a peak of $0.600(0.548-0.652)$ in $1967 / 68$ to 0.352 $(0.313-0.391)$ in $2010 / 11$, with a slight increase predicted thereafter to $0.363(0.300-0.426)$ in 2019/20 (Fig. 4i).

\section{Discussion}

The long-term monitoring of demographic changes in European waterbird populations remains limited. Yet, such information can be very valuable for conservationists and waterbird managers (Donald 2007). In this study, we used data from individual birds captured over a 57 year period to assess the extent of, and temporal variability in, male-bias in 9 populations of ducks wintering in the United Kingdom.

We found that most wintering duck populations were male biased. When adults and first-winter juveniles were considered together, we found that eight out of our nine focal species had male-biased sex ratios, offering strong support for our first prediction. Indeed, Tufted Duck was the only species not to show a male bias. These results from assessments of individuals that were captured for ringing concur with previous observational studies that have also documented the prevalence of male bias among wintering duck populations (e.g. Bellrose et al. 1961; Owen and Dix 1986; Mitchell et al. 2008; Brides et al. 2017; Frew et al. 2018).

Male bias was greater among adults than first-winter juveniles in all nine focal species, in accordance with our second prediction. We found mixed support for our third hypothesis, that male bias would have increased over time among adults but not first-winter juveniles; male bias increased among adult Northern Mallard, Northern Pintail, Common Pochard, Common Shelduck, and Tufted Duck, but also among both adult and first-winter 
juvenile Northern Shoveler. It should also be noted that, given the ecological differences among our nine focal populations, there is unlikely to be a single mechanism that was responsible for male-bias, or for the increase in male bias over time where this was detected. Instead, across the nine populations there may be multiple determinants of the sex ratios, and detailed population-specific studies will be required to elucidate those factors.

The increased male bias among adults is consistent with the hypothesis that the predation of reproductiveage females during the breeding season is a contributor to the observed male bias (Johnson and Sergeant 1977; Ramula et al. 2018). Nesting females are vulnerable to predators whilst on their nest, whereas males play no role in incubation or brood rearing, and so such predation results in higher mortality rates of females relative to males (Ramula et al. 2018). Such predators of nesting and incubating female ducks within Europe include nonnative mammals such as Racoon Dog (Nyctereutes procyonoides) and American Mink (Mustela vison), as well as native mammals such as Red Fox (Vulpes vulpes) (Blums and Mednis 1996; Opermanis et al. 2001; Albrecht et al. 2006).

The sex ratios of first-winter juveniles were, in general, less male-biased, and for some populations even showed a female bias. Whilst the sex ratios of first-winter juveniles were closer to parity when compared with adults, nevertheless we detected male-biased sex ratios among first-winter Common Pochard, Northern Shoveler, and Eurasian Teal. First-winter juveniles have not yet attempted breeding, and so the existence of male bias among these birds cannot be explained by predation on the breeding grounds. Alternative explanations must be sought instead, such as differential patterns of migration or non-predation mortality between males and females.

For duck species that are widely distributed across Europe, differential migration patterns are frequently observed for males and females (Perdeck and Cavé 1983; Evans and Day 2001). Females are more likely than males to select winter sites that are further south, which likely reflects the competitive dominance of males at feeding sites (Choudhury and Black 1991; Carbone and Owen 1995). Within the winter ranges of our study species, the UK has a relatively northerly latitude, and so differential migration could have contributed to the male-biased sex ratios among both adults and first-winter juveniles that were detected in our study.

While shooting can remove both male and female individuals, for some populations the effects of shooting on the sex ratio may be more complex. For many species of ducks in which the males have more brightly-coloured plumage compared with females, there is evidence that these males are more likely to be shot by hunters (Metz and Ankney 1991). Sex-selective shooting mortality could have contributed to the female-biased sex ratios that we found for some of our first-winter juvenile ducks, such as Northern Pintail, Tufted Duck, and Eurasian Wigeon. However, any such effects must have been offset among adult birds by other processes, such as predation of nesting females, which resulted in male-biased adult populations. Female-biased sex ratios among fledged juveniles may also result from sex-differential mortality among juveniles, whereby among sexually-dimorphic birds mortality is typically higher in the larger sex (Székely et al. 2014). Such differences in juvenile survival rates are thought to reflect the greater sensitivity of the larger sex to food shortages (Clutton-Brock 1986). All of our focal duck species were sexually dimorphic, with males having typically larger body size than females (Kear and Hulme 2005), although female-biased sex ratios among first-winter juveniles were only detected in three species: Northern Pintail, Tufted Duck, and Eurasian Wigeon. Further research would be needed, however, to investigate any potential link between available food resources, juvenile duck survival rates, and resulting sex ratio biases.

While the number of studies of adults and fledged juveniles is growing, there have been relatively few studies of the sex ratio at earlier life stages of ducks, such as embryos and hatchlings. In one relevant example, Blums and Mednis (1996) found that the numbers of male and female hatchlings were similar for all three duck species studied, Common Pochard, Northern Shoveler, and Tufted Duck, suggesting a balanced sex ratio among hatchling ducks. Lehikoinen et al. (2008b) similarly reported parity in the hatchling sex ratio of Common Eider. In contrast, Ramula et al. (2018) detected a marginal female bias in the hatchling sex ratio of Common Eider. There is no evidence therefore to suggest that the strongly male-biased sex ratios in most adult and some first-winter juvenile duck populations results from entrained differences at earlier life stages, but instead must be generated by demographic processes (e.g. sex differential mortality) that occur post-fledging. However, more spatially and temporally replicated studies of the sex ratios of early life stages would help to improve our understanding of how male bias develops in duck populations.

A key assumption of our study is that the sex ratio among individuals captured for ringing reflects the sex ratio in the total wintering population. Sex biases among capture methods could confound any assessment of sex ratios in bird populations (e.g. Cooper et al. 2019). Competitive dominance of males among some duck species (Choudhury and Black 1991; Wood et al. 2017) clearly did not prevent the capture of females during our study. Crucially, our study found levels of bias in the sex ratio that were 
comparable with observational studies carried over within the same time period within the UK (e.g. Owen and Dix 1986; Carbone and Owen 1995; Brides et al. 2017; Frew et al. 2018), which suggests that our capture methodology was not biased towards males. We conclude, therefore, that the male bias reported in our study reflects real biological patterns rather than artefacts of our sampling procedures. Interpretation of the temporal patterns in male bias for Northern Mallard are potentially complicated by the release of unknown numbers of captive-reared individuals for recreational shooting, which mix with the wild birds (Aebischer 2019). However, there is little information on the total numbers or sex ratio of those released, and so the implications of captive releases for the sex ratio of the Northern Mallard population are unknown.

\section{Conclusions}

Our study has demonstrated that birds caught during ringing projects can be a valuable source of sex ratio data. As individual sex and age for most duck species can be determined from a visual inspection of the wing, the wings of hunted birds may also provide a valuable source of data for assessing trends in the sex ratios of waterbird populations (Christensen and Fox 2014). Both birds captured for ringing and hunted birds could be used to complement assessments of sex ratios based on observational methods (Owen and Dix 1986; Brides et al. 2017; Frew et al. 2018). The collection of data on the relative numbers of males and females within waterbird populations through existing national and international monitoring networks could enable annual assessments of the sex ratios for many common waterbird species, and could become a routinely included element of international waterbird counts. More comprehensive flyway-scale monitoring of the sex ratios of wintering waterbirds, including consideration of age classes, would help to improve our understanding of changes in waterbird demography and population trends (Donald 2007).

\section{Supplementary Information}

The online version contains supplementary material available at https://doi. org/10.1186/s40657-021-00286-1.

\footnotetext{
Additional file 1: Figure S1. Latitude-date correlations for each species. Table S1. Sample sizes for all species. Table S2a. Gadwall male likelihood candidate models. Table S2b. Northern Mallard male likelihood candidate models. Table S2c. Northern Pintail male likelihood candidate models. Table S2d. Common Pochard male likelihood candidate models. Table S2e. Common Shelduck male likelihood candidate models. Table S2f. Northern Shoveler male likelihood candidate models. Table S2g. Eurasian Teal male likelihood candidate models. Table S2h. Tufted Duck male likelihood candidate models. Table S2i. Eurasian Wigeon male likelihood candidate models. Table S3. Parameter estimates for each species.
}

\section{Acknowledgements}

We are grateful to the many individuals who helped to collect and collate the data that were used in this study. We thank the editor and three anonymous reviewers for their constructive feedback on our work.

\section{Authors' contributions}

$\mathrm{KAW}, \mathrm{KB}, \mathrm{MED}$ and $\mathrm{RDH}$ conceived and designed the study. KB and MED collated the data. KAW carried out the analyses. KAW, KB, MED and RDH wrote the manuscript. All authors read and approved the final manuscript.

\section{Funding}

This study was supported by the Wildfowl \& Wetlands Trust.

\section{Availability of data and materials}

The datasets analysed during the current study are available from the corresponding author upon reasonable request.

\section{Declarations}

Ethics approval and consent to participate

The procedures employed in this study complied with the laws of the United Kingdom, where they were carried out. Capture and handling of the ducks was undertaken by individuals licensed by the British Trust for Ornithology.

\section{Consent for publication}

Not applicable.

\section{Competing interests}

The authors declare that they have no competing interests.

Received: 27 May 2021 Accepted: 27 September 2021

Published online: 05 October 2021

\section{References}

Aebischer NJ. Fifty-year trends in UK hunting bags of birds and mammals, and calibrated estimation of national bag size, using GWCT's National Gamebag Census. Eur J Wildl Res. 2019;65:64.

Albrecht T, Hořák D, Kreisinger J, Weidinger K, Klvaňa P, Michot TC. Factors determining pochard nest predation along a wetland gradient. J Wildlife Manag. 2006;70:784-91.

Alexander WC. Differential sex distributions of wintering diving ducks (Aythyini) in North America. Am Birds. 1983;37:26-9.

Arnold TW. Uninformative parameters and model selection using Akaike's Information Criterion. J Wildlife Manag. 2010;74:1175-8.

Bartoń K. MuMIn: Model selection and model averaging based on information criteria. R package version 1.13.4. 2012. https://cran.r-project.org/packa ge=MuMln.

Bates D, Mächler M, Bolker BM, Walker SC. Fitting linear mixed-effects models using Ime4. J Stat Software. 2015;67:1-48.

Bellebaum J, Mädlow W. Survival explains sex ratio in an introduced Mandarin Duck Aix galericulata population. Ardea. 2015;103:183-7.

Bellrose FC, Scott TG, Hawkins AS, Low JB. Sex ratios and age ratios in North American ducks. III Nat Hist Surv Bull. 1961;27:391-486.

Blums P, Mednis A. Secondary sex ratio in Anatinae. Auk. 1996;113:505-11.

Bolen EG. Sex ratios in the Black-bellied Tree Duck. J Wildlife Manag. 1970;34:68-73

Brides K, Wood KA, Hearn RD, Fijen TPM. Changes in the sex ratio of the Common Pochard Aythya ferina in Europe and North Africa. Wildfowl. 2017:67:100-12.

Burnham KP, Anderson DR, Huyvaert KP. AIC model selection and multimodel inference in behavioral ecology: some background, observations, and comparisons. Behav Ecol Sociobiol. 2011;65:23-35.

Carbone C, Owen M. Differential migration of the sexes of Pochard Aythya ferina: results from a European survey. Wildfowl. 1995;46:99-108.

Carney SM. Species, age and sex identification of ducks using wing plumage. Washington: US Department of the Interior, US Fish and Wildlife Service; 1992. 
Choudhury S, Black JM. Testing the behavioural dominance and dispersal hypothesis in Pochard. Ornis Scand. 1991;22:155-9.

Christensen TK, Fox AD. Changes in age and sex ratios amongst samples of hunter-shot wings from common duck species in Denmark 1982-2010. Eur J Wildl Res. 2014;60:303-12.

Clutton-Brock TH. Sex-ratio variation in birds. Ibis. 1986;128:317-29.

Cooper N, Bond AL, Davis JL, Portela Miguez R, Tomsett L, Helgen KM. Sex biases in bird and mammal natural history collections. Proc R Soc B. 2019:286:20192025.

Cox DR, Snell EJ. Analysis of binary data. 2nd ed. Boca Raton: Chapman and Hall; 1989.

Crawley MJ. Statistics: an introduction using R. Chichester: Wiley; 2005

Dean WRJ, Skead DM. The sex ratio in Yellowbilled Duck, Redbilled Teal and Southern Pochard. Ostrich. 1977:48:82-5.

Donald PF. Adult sex ratios in wild bird populations. Ibis. 2007;149:671-92.

Dormann CF, Elith J, Bacher S, Buchmann C, Carl G, Carré G, et al. Collinearity: a review of methods to deal with it and a simulation study evaluating their performance. Ecography. 2013;36:27-46.

Eberhart-Phillips LJ, Küpper C, Carmona-Isunza MC, Vincze O, Zefania S, CruzLópez $M$, et al. Demographic causes of adult sex ratio variation and their consequences for parental cooperation. Nat Commun. 2018;9:1651.

Evans DM, Day KR. Migration patterns and sex ratios of diving ducks wintering in Northern Ireland with specific reference to Lough Neagh. Ringing Migr 2001;20:358-63.

Fox AD, Cristensen TK. Could falling female sex ratios among first-winter northwest European duck populations contribute to skewed adult sex ratios and overall population declines? Ibis. 2018;160:929-35.

Fox AD, King R, Watkin J. Seasonal variation in weight, body measurements and condition of free-living Teal. Bird Study. 1992;39:53-62.

Frew RT, Brides K, Clare T, Maclean L, Rigby D, Tomlinson CT, et al. Temporal changes in the sex ratio of the Common Pochard Aythya ferina compared to four other duck species at Martin Mere, Lancashire, UK. Wildfowl. 2018;68:140-54

Guillemain M, Fox AD, Pöysä H, Väänänen V-M, Christensen TK, Triplet P, et al. Autumn survival inferred from wing age ratios: Wigeon juvenile survival half that of adults at best? J Ornithol. 2013:154:351-8.

Hommel G. A stagewise rejective multiple test procedure based on a modified Bonferroni test. Biometrika. 1988;75:383-6.

Johnson DH, Sargeant AB. Impact of red fox predation on the sex ratio of prairie mallards. Washington: Department of the Interior, Fish and Wildlife Service; 1977.

Kear J, Hulme M. Ducks, geese and swans. Oxford: Oxford University Press; 2005

Ketterson ED, Nolan V Jr. Geographic variation and its climatic correlates in the sex ratio of eastern-wintering Dark-eyed Juncos (Junco hyemalis hyemalis). Ecology. 1976;57:679-93.

Korschgen CE. Breeding stress of female eiders in Maine. J Wildl Manag. 1977:41:360-73.

Lehikoinen A, Christensen TK, Öst M, Kilpi M, Saurola P, Vattulainen A. Largescale change in the sex ratio of a declining eider Somateria mollissima population. Wildlife Biol. 2008a;14:288-301.

Lehikoinen A, Öst M, Hollmén T, Kilpi M. Does sex-specific duckling mortality contribute to male bias in adult common eiders. Condor. 2008b;110:574-8.
Leopold A. Game management. Madison: The University of Wisconsin Press; 1933.

Madge S, Burn H. Wildfowl: an identification guide to the ducks, geese and swans of the world. London: Christopher Helm; 1988.

Mayr E. The sex ratio in wild birds. Am Nat. 1939;73:156-79.

Metz KJ, Ankney CD. Are brightly coloured male ducks selectively shot by duck hunters? Can J Zool. 1991;69:279-82.

Mitchell C, Ogilvie M. Fifty years of wildfowl ringing by The Wildfowl \& Wetlands Trust. Wildfowl. 1996:47:240-7.

Mitchell C, Fox AD, Harradine J, Clausager I. Measures of annual breeding success amongst Eurasian Wigeon Anas penelope. Bird Study. 2008:55:43-51.

Nagelkerke NJD. A note on a general definition of the coefficient of determination. Biometrika. 1991;78:691-2.

Opermanis O, Mednis A, Bauga I. Duck nests and predators: interaction, specialisation and possible management. Wildlife Biol. 2001;7:87-96.

Owen $\mathrm{M}$, Cook WA. Variations in body weight, wing length and condition of Mallard Anas platvrhvnchos platyrhynchos and their relationship to environmental changes. J Zool. 1977;183:377-95.

Owen M, Dix M. Sex ratios in some common British wintering ducks. Wildfowl. 1986:37:104-12.

Owen M, Mitchell C. Movements and migrations of Wigeon Anas penelope wintering in Britain and Ireland. Bird Study. 1988;35:47-59.

Owen M, Montgomery S. Body measurements of Mallard caught in Britain. Wildfowl. 1978;29:123-34

Perdeck AC, Cavé AJ. Sexual differences in migration and winter quarters of ducks ringed in the Netherlands. Wildfowl. 1983;34:137-43.

Pöysä H, Linkola P, Paasivaara A. Breeding sex ratios in two declining diving duck species: between-year variation and changes over six decades. J Ornithol. 2019;160:1015-23.

R Core Team. R: a language and environment for statistical computing [3.6.3] Vienna, Austria: R Foundation for Statistical Computing; 2020. http:// www.R-project.org/.

Ramula S, Öst M, Lindén A, Karell P, Kilpi M. Increased male bias in eider ducks can be explained by sex-specific survival of prime-age breeders. PLoS One. 2018;13:e0195415.

Scott P. The decoy. Severn Wildfowl Trust Ann Rep. 1949;1:57-61.

Sheldon BC. Recent studies of avian sex ratios. Heredity. 1998;80:397-402.

Signorell A. DescTools: tools for descriptive statistics. R package version 0.99.37. 2020. https://cran.r-project.org/package=DescTools.

Sun YH, Bridgman CL, Wu HL, Lee CF, Liu M, Chiang PJ, et al. Sex ratio and survival of Mandarin Ducks in the Tachia River of central Taiwan. Waterbirds. 2011:34:509-13.

Székely T, Weissing FJ, Komdeur J. Adult sex ratio variation: implications for breeding system evolution. J Evol Biol. 2014;27:1500-12.

Thompson MC, DeLong RL. The use of cannon and rocket-projected nets for trapping shorebirds. Bird-Banding. 1967;38:214-8.

Wainwright CB. How to make and use duck traps. Wildfowl. 1957:8:44-7.

Wood KA, Ponting J, D'Costa N, Newth JL, Rose PE, Glazov P, et al. Understanding intrinsic and extrinsic drivers of aggressive behaviour in waterbird assemblages: a meta-analysis. Anim Behav. 2017;126:209-16.

Ready to submit your research? Choose BMC and benefit from

- fast, convenient online submission

- thorough peer review by experienced researchers in your field

- rapid publication on acceptance

- support for research data, including large and complex data types

- gold Open Access which fosters wider collaboration and increased citations

- maximum visibility for your research: over 100M website views per year

At BMC, research is always in progress.

Learn more biomedcentral.com/submissions 